\title{
Determining the Behavior of Door Impact Beam Tubes Under Three Point Bending Loading
}

\author{
Oğuz Can Karahan ${ }^{1}$ and Emre Esener ${ }^{1 *}$ \\ 0000-0003-2585-6617, 0000-0001-5854-4834 \\ ${ }^{1}$ Mechanical Engineering Department, Faculty of Engineering, Bilecik Seyh Edebali University, Bilecik, 11210, Turkey
}

\begin{abstract}
In real crash cases, simple bending behavior is not common. In this case, using the threepoint bending test to examine the bending behavior provides a closer simulation in terms of the representation of the structure under loading. It is seen in the literature that products with tube sections are generally used as door impact beams. On the other hand, when examining the three-point bending behavior of developed high strength steels, it is seen that the studies on tube profiles are only evaluated in terms of hydroforming. In this study, dual-phase steel tubes used as door impact beams are investigated by means of bending loading with experimental and numerical studies. For this purpose, DP500 and DP600 steel grades are used as materials. Three-point bending tests are performed for both materials then force-stroke curves, and springback values are obtained experimentally. In the second stage of the study, finite element analyses are performed using Hill-48 plasticity model. Force-stroke curves, the amount of springback, and the product forms are compared with the experimental results. It is seen that force-stroke curves and product forms are obtained highly compatible with the experimental results however the amount of springback values in finite element analyses are determined higher than the experimental results.
\end{abstract}

Keywords: Door impact beam, Dual phase steel, Finite element analyses, Three-point bending.

\section{Research Article}

https://doi.org/10.30939/ijastech..826458

$\begin{array}{lr}\text { Received } & 16.10 .2020 \\ \text { Revised } & 27.12 .2021 \\ \text { Accepted } & 29.12 .2021\end{array}$

Accepted 29.12.2021

* Corresponding author

Emre Esener

emre.esener@bilecik.edu.tr

Address: Mechanical Engineering Department, Faculty of Engineering, Bilecik Seyh Edebali University, Bilecik, Turkey

Tel:+903122028653

\section{Introduction}

Today, traffic accidents are among the leading causes of human death. Deaths and injuries caused by traffic accidents can be brought under control if adequate attention is paid to accident and injury prevention strategies. For this reason, automobile manufacturers have created components that increase safety in the event of a collision, such as airbags, energy-absorbing steering columns, side door impact beams. Side collisions as a secondary critical crash zone after frontal collisions in vehicles are seen as the main cause of death and injuries in traffic accidents [1]. For this reason, developments in the automotive industry are mainly focused on vehicles with high crash resistance and light weight [2]. Studies carried out in the 1960s showed that side collisions are more vulnerable in traffic accidents due to the shorter distance between the door and the passenger compared to a frontal collision in the compartment area on the driver's side [3]. For this reason, General Motors first added a support beam to the side doors of its cars in order to reduce the severity of the impact to the passenger compartment and passengers [4]. The materials of these support beams are expected to have high crash resistance and high toughness. The automotive industry has been in search of materials that can meet these needs.

When the steel material group is evaluated together with the weight / strength ratios, it stands out from the non-ferrous materials in terms of critical collisions. In the steel industry, especially after the production of advanced high strength steels (AHSS), these steels have started to take their place in the automotive sector. Among the advanced high strength steels, the steel group named as dual phase (DP) steel has started to be preferred more than other AHSS steels due to their weight / strength ratio and good weldability in assembly [5]. Dual phase (DP) steels are a group of steels that contain ferrite and martensite phases, and the hard martensite phase in its internal structure is found in the form of islands in a soft ferrite matrix in areas close to the grain boundaries. In this way, a steel group with high strength and improved deformation capability was obtained. Compared to the high strength low alloy (HSLA) steel group, which has been used before in DP steels, dual phase steels show more deformation ability at the same strength values [6].

With the use of compliance standards such as Euro NCAP and FMVSS (Federal Motor Vehicle Safety Standard-214), it has been 
inevitable for vehicle manufacturers to take precautions in this regard, with the use of compliance standards in automobiles, based on certain standards by taking the initiative of the manufacturer and performing side crash tests under these standards. In side crash tests, an element that can be considered as rigid body collides with the side area of the vehicle at certain speeds [7]. As a result of this collision effect, the side door reinforcement beams inside the door are exposed to bending force [4]. According to the loading conditions, the bending of the beams can be basically classified into two groups as simple bending and three-point bending. In real crash cases, simple bending behavior is not common. In this case, using the three-point bending test to examine the bending behavior provides a closer simulation in terms of the representation of the structure under loading [8]. It is seen in the literature that products with tube profile sections are generally used as door impact beams [911]. On the other hand, when examining the three-point bending behavior of developed high strength steels, it is seen that the studies on hollow profiles (tubes, etc.) are only evaluated in terms of hydroforming $[5,12]$.

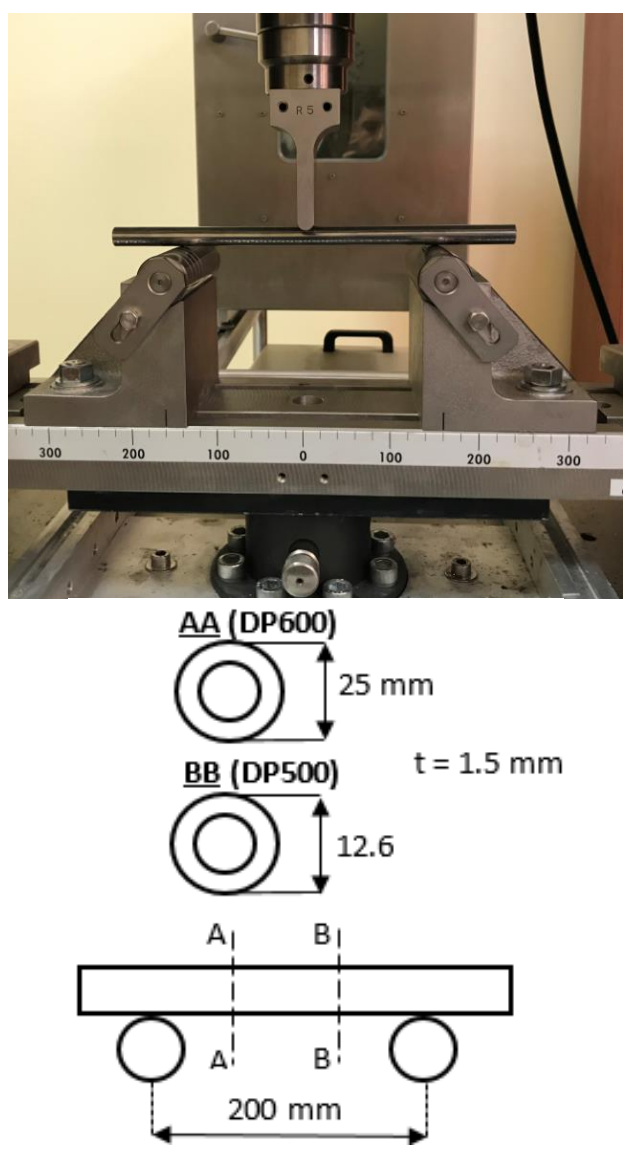

Fig. 1. Experimental setup and schematically view of three-point bending system

In this study, the behavior of the tubular DP500 and DP600 quality materials used as door impact beams under three-point bending was experimentally and numerically investigated. In this sense, displacement-dependent variations of forming forces, springback behavior and product forms after three-point bending were evaluated.

\section{Experimental Studies}

In this study, three-point bending tests have been applied to dual phase tubes with DP500 and DP600 qualities. In experiments, forming speed was applied as $10 \mathrm{~mm} / \mathrm{min}$ constant. The distance between the supports (spans) was used as $200 \mathrm{~mm}$. The outer diameter of the tubes was $12.6 \mathrm{~mm}$ for DP500 and $25 \mathrm{~mm}$ for DP600 and the wall thickness of both materials was $1.5 \mathrm{~mm}$. Three-point bending tests were carried out in a Shimadzu AG-X tensile test machine. Experimental setup and schematically view of threepoint bending system are given in Figure 1. After the experiments, the variation of the forming force depending on the stroke was obtained and the forming force-stroke curves of both materials are shown in Figure 2. Within the scope of the experimental study, as the last parameter, after the three-point bending deformation, the springback values of both materials were determined using a protractor and these values were obtained as $5^{\circ}$ for DP500 and $20^{\circ}$ for DP600. The schematic of springback measurements is shown in Figure 3.

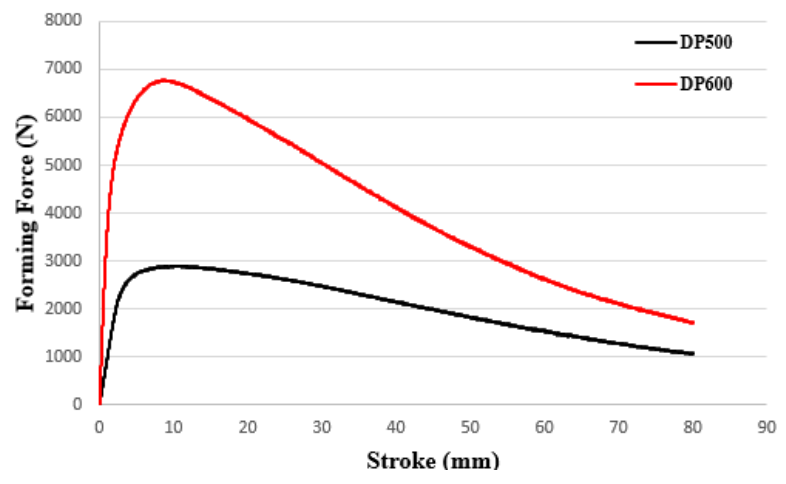

Fig. 2. Comparison of experimental forming force-stroke curves

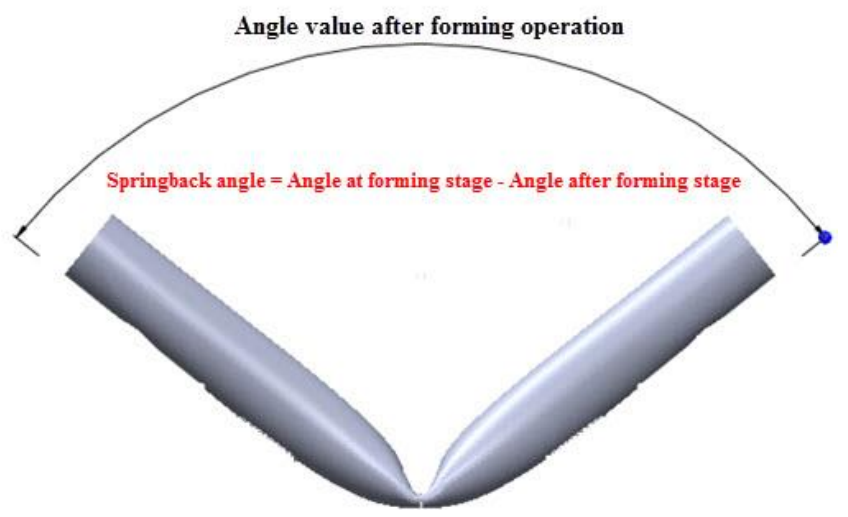

Fig. 3. The schematic of springback measurements 


\section{Finite Element Analyses}

In the next stage of the study, the three-point bending process is analyzed numerically in terms of both materials. In this context, finite element analysis (FEA) was used, and the simulations of the study were carried out in Ls-Dyna / Dynaform commercial software. In this sense, the process is considered as a plane strain problem and the span and punch parts are modeled as rigid body, and the tube geometry is modeled using shell elements. Finite element model of the process is given in Figure 4. In this context, 504 shell elements were used in each of the span parts, and 392 shell elements are used in the punch geometry. In tube parts, 8500 shell elements were used for DP500 and 18500 shell elements were used for DP600 steel.

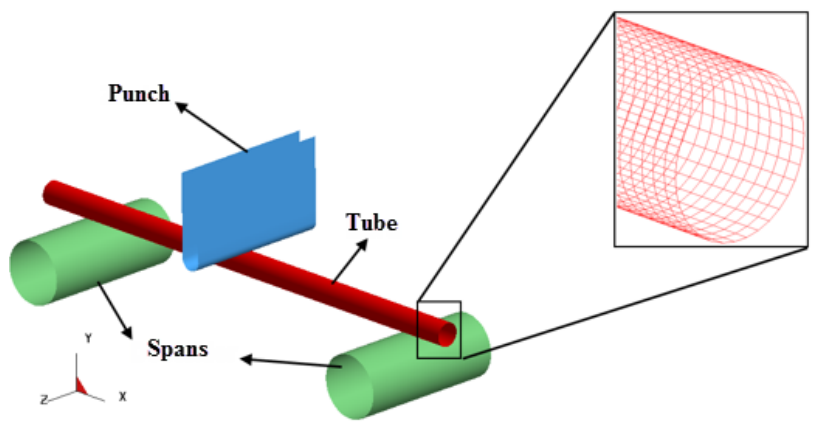

Fig. 4. Finite element model of three-point bending process

In finite element analysis, a yield criterion, a hardening rule, and a flow rule are composed to model the plastic behavior of materials, and these plasticity models are very effective on finite element prediction results [13]. In this respect, Hill (1948) model, which is one of the most frequently used plasticity models, was used for both materials. The Hill-48 model is a criterion that considers material anisotropy based on the von Mises yield criterion [14]. In the most general form, Hill-48 criterion can be written as in Equation (1).

$$
\begin{aligned}
& F\left(\sigma_{22}-\sigma_{33}\right)^{2}+G\left(\sigma_{33}-\sigma_{11}\right)^{2}+ \\
& H\left(\sigma_{11}-\sigma_{22}\right)^{2}+2 L \sigma_{23}^{2}+2 M \sigma_{31}^{2}+ \\
& 2 N \sigma_{12}^{2}-1=0
\end{aligned}
$$

The plane stress form of the Hill-48 model can be written as in Equation (2). F, G, $\mathrm{H}$ and $\mathrm{N}$ parameters in this equation are coefficients depending on Lankford parameters and these coefficients can be calculated as in Equations (3)-(5).

$$
\begin{aligned}
& F\left(\sigma_{22}\right)^{2}+G\left(\sigma_{11}\right)^{2}+H\left(\sigma_{11}-\sigma_{22}\right)^{2}+ \\
& 2 N \sigma_{12}^{2}-1=0 \\
& r_{0}=H / G \\
& r_{90}=H / F
\end{aligned}
$$

$$
\sigma_{45}=\frac{H}{F+G}-\frac{1}{2}
$$

In this sense, the mechanical properties used in the Hill-48 model for the DP500 and DP600 materials used in the study are given in Table 1.

Table 1. Material properties of materials $[15,16]$.

\begin{tabular}{c|c|c}
\hline Mechanical Property & DP500 & DP600 \\
\hline Young's modulus [GPa] & 207 & 207 \\
\hline Poisson's ratio & 0.28 & 0.28 \\
\hline Yield Strength [MPa] & 351 & 439 \\
\hline Strength Coefficient (K) [MPa] & 731.10 & 1037 \\
\hline Hardening Exponent (n) & 0.14 & 0.15 \\
\hline $\mathrm{r}_{0}$ & 0.95 & 1.16 \\
\hline $\mathrm{r}_{45}$ & 0.81 & 0.67 \\
\hline $\mathrm{r}_{90}$ & 1.10 & 1.02 \\
\hline
\end{tabular}

Within the scope of finite element analysis, Belytschko-Tsay element formulation and 7 integration points in thickness direction were used as calculation parameters, and the punch velocity was $2000 \mathrm{~mm} / \mathrm{s}$. In order to perform the experimental verification of the simulations, firstly, the forming force-stroke curves were obtained, and the comparison results are given in Figure 5. The second comparison is made in terms of springback values, and the comparison of springback angle values of experimental and finite element analysis results is given in Table 2. Finally, the product forms were compared with the forms obtained from finite element analysis, and the results of this comparison are shown in Figure 6 and Figure 7 for both materials, respectively.

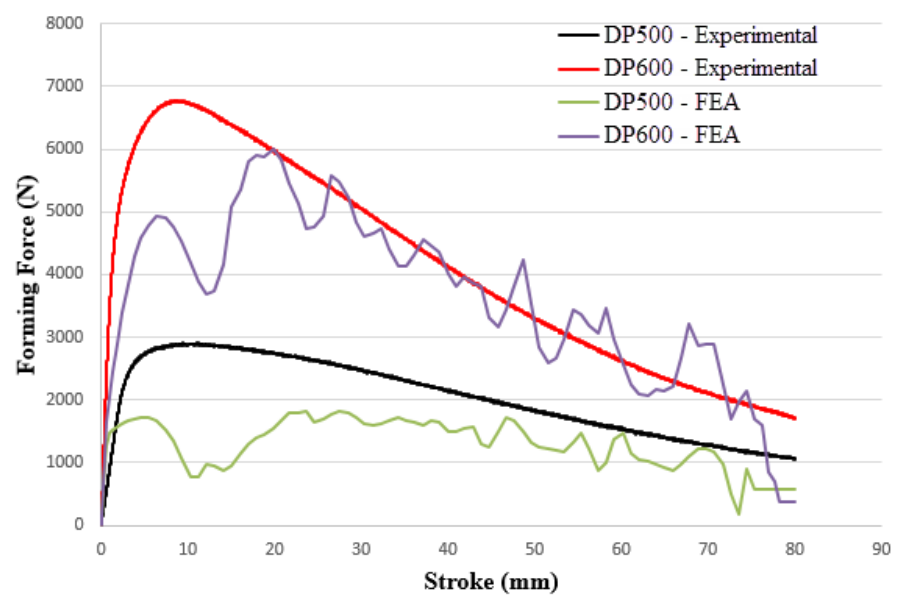

Fig. 5. Comparison of forming force - stroke curves 
Table 2. Comparison of springback angles after three-point bending process

\begin{tabular}{c|c|c}
\hline \multirow{2}{*}{ Material } & \multicolumn{2}{|c}{ Springback Angle $\left(^{\circ}\right)$} \\
\cline { 2 - 3 } & Experiment & FEA \\
\hline DP500 & 5 & 11 \\
\hline DP600 & 20 & 28 \\
\hline
\end{tabular}

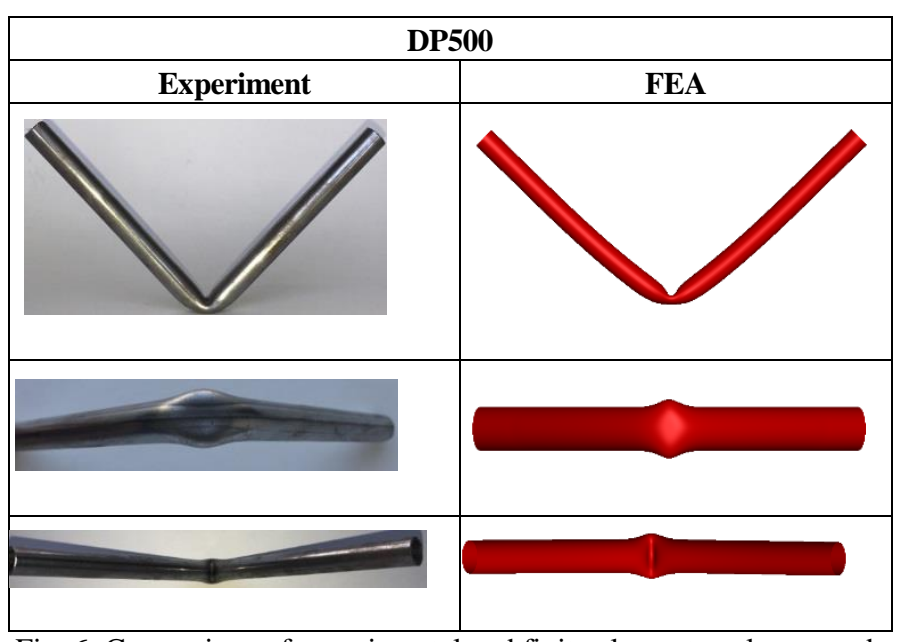

Fig. 6. Comparison of experimental and finite element analyses product forms for DP500 tube

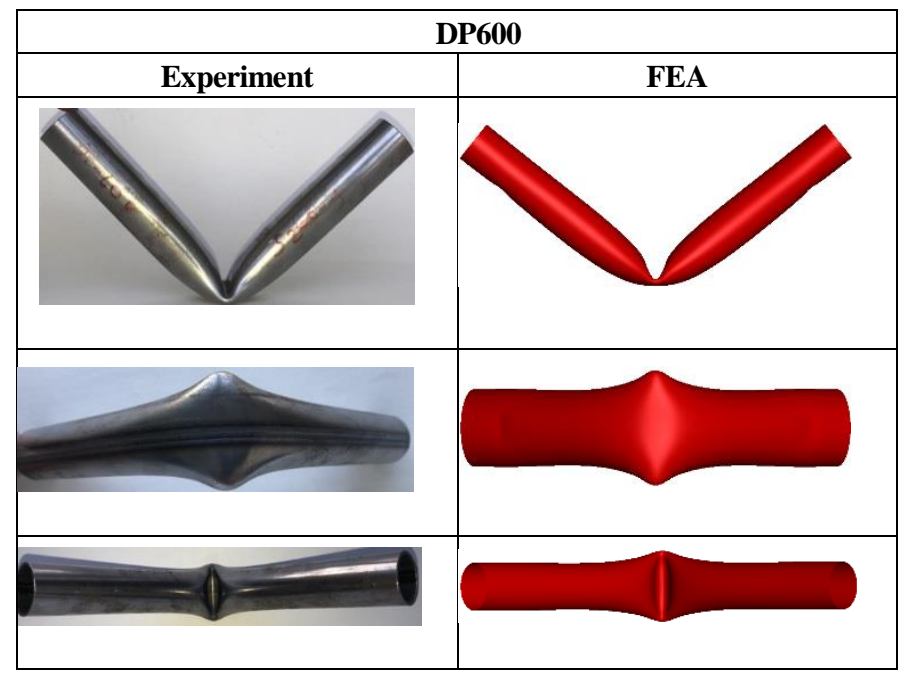

Fig. 7. Comparison of experimental and finite element analyses product forms for DP600 tube

\section{Conclusions}

In this study, three-point bending tests of DP500 and DP600 tube materials were carried out and their behavior under bending was investigated experimentally and numerically. When the results are evaluated, it was experimentally seen by force-stroke curves that the DP600 material should be formed with more force than DP500 in the same forming stroke. Considering the results of the finite element analysis, it was determined that the force-stroke curves were compatible with the experimental tendency for both materials, but the force estimation was lower in the finite element analysis in terms of maximum force compared to the experiments. It is thought that this situation is caused by the plasticity model that defines the material plastic behavior and the element formulation, which is one of the finite element calculation parameters.

Considering the product forms, it was seen that finite element analysis for both materials was quite successful. For both materials, the product form was obtained in accordance with the experimental results in terms of wrinkle zones and section constriction. When the spring-back angle values are examined as the last parameter, it was seen that the springback results in finite element analysis are higher than the experimental data, this situation is caused by the plasticity model used in finite element analyses.

\section{Conflict of Interest Statement}

The authors declare that there is no conflict of interest.

\section{CRediT Author Statement}

Oğuz Can Karahan: Conceptualization, Formal analysis, Data curation, Writing-original draft, Emre Esener: Conceptualization, Writing-original draft, Supervision, Validation

\section{Nomenclature}

$\begin{array}{ll}\text { AHSS } & : \text { Advanced High Strength Steel } \\ \mathrm{K} & : \text { Strength coefficient } \\ \mathrm{n} & : \text { Hardening exponent } \\ \mathrm{r}_{0}, \mathrm{r}_{45}, \mathrm{r}_{90} & : \text { Lankford parameters } \\ \mathrm{F}, \mathrm{G}, \mathrm{H}, \mathrm{N} & : \text { Hill-48 coefficients }\end{array}$

\section{References}

[1] Nemani R, Arakerimath R R. Taguchi based design optimization of side impact beam for energy absorption. Int J Adv Res in Eng and Technol. 2015; 3(9):100-104.

[2] Li M F, Chiang T S, Tseng J H, Tsai C N. Hot stamping of door impact beam. Procedia Engineering. 11th International Conference on Technology of Plasticity, 19-24 October 2014, Nagoya Congress Center, Nagoya, Japan. 2014; pp. 1786-1791.

[3] Shaharuzaman M A, Sapuan S M, Mansor M R, Zuhri M Y M. Passenger Car's Side Door Impact Beam: A Review. J of Eng and Technol. 2018; 9, 1.

[4] Lim T S. Mechanically fastened composite side-door impact beams for passenger cars designed for shear-out failure modes. Comp Struct, 2002; 56(2):211-221.

[5] Pavlina E J, Van Tyne C J, Hertel K. Hydraulic bulge testing of dual phase steel tubes produced using a novel processing route. J Mater Proces Technol. 2008; 201(1-3):242-246.

[6] Oliver C. (Dual Phase Steel Characterization for Tube Bending and Hydroforming Applications. MSc Thesis, University of Windsor, Mechanical, Automotive \& Materials Engineering, 2010.

[7] Ghadianlou A, Abdullah S B. Crashworthiness design of vehicle side door beams under low-speed pole side impacts. Thin-Wall Struct. 2013; 67:25-33. 
[8] Kayacan R. 3 Nokta Eğme Deney Raporu. Süleyman Demirel Üniversitesi, Mühendislik Fakültesi, Makine Mühendisliği Bölümü, Isparta, Türkiye, 2015.

[9] Sadighi A, Eyvazian A, Asgari M, Hamouda A M. A novel axially half corrugated thin-walled tube for energy absorption under axial loading. Thin-Wall Struct. 2019; 145,106418.

[10] Guo L, Liu Y, Fu F, Huang H. Behavior of axially loaded circular stainless-steel tube confined concrete stub columns. Thin-Wall Struct. 2019; 139:66-76.

[11] Nikkhah H, Baroutaji A, Olabi A G Crashworthiness design and optimization of windowed tubes under axial impact loading. ThinWall Struct. 2019; 142:132-148.

[12] Huang Z, Zhang X. Three-point bending collapse of thin-walled rectangular beams. Int J Mech Sci. 2018; 144:461-479.

[13] Ozsoy M, Esener E, Ercan S, Firat M. Springback predictions of a dual-phase steel considering elasticity evolution in stamping process. Arabian J Sci and Eng. 2014; 39(4):3199-3207.

[14] Hill R. A theory of The Yielding and Plastic Flow of Anisotropic Materials, Proc Roy Soc London. 1948; 281-297.

[15] Zang S L, Thuillier S, Le Port A, Manach P Y. Prediction of anisotropy and hardening for metallic sheets in tension, simple shear and biaxial tension. Int J Mech Sci. 2011; 53(5):338-347.

[16] Ghaei A, Green D E, Taherizadeh A. Semi-implicit numerical integration of Yoshida-Uemori two-surface plasticity model. Int $\mathbf{J}$ Mech Sci. 2010; 52(4):531-540. 